\title{
Reprodução de Discursos Racistas \\ em Textos de Discentes do Instituto Federal Farroupilha - São Vicente do Sul/RS
}

http://dx.doi.org/10.21527/2237-6453.2019.48.300-311

Recebido em: 21/9/2017

Aceito em: 19/3/2019

Laís Braga Costa, ${ }^{1}$ Sirlei de Lourdes Lauxen, ${ }^{2}$ Marcel Jardim Amaral ${ }^{3}$

\begin{abstract}
RESUMO
O presente artigo tomou por base textos produzidos por alunos do Ensino Médio do Instituto Federal Farroupilha, Campus de São Vicente do Sul, na disciplina de Língua Portuguesa. A questão central da discussão está baseada na análise sobre a reprodução de discursos racistas trazidos pelos textos dos discentes. Por se tratar de uma pesquisa social, é de natureza qualitativa, conforme Minayo (2001). O texto discute a questão étnica no Brasil, a perspectiva política dos discursos e a realidade sociocultural da comunidade que compõe o IFFar. O aporte teórico foi constituído a partir de autores como Davis (2016), Freire (1996), Santos (2010), entre outros. Como conclusão apresenta-se a necessidade da discussão sobre racismo na escola para fomentar a empatia com os grupos étnicos não dominantes.
\end{abstract}

Palavras-chave: Discurso. Educação. Racismo.

REPRODUCTION OF RACIST SPEECHES IN TEXTS OF STUDENTS OF THE INSTITUTO FEDERAL FARROUPILHA - SÃO VICENTE DO SUL/RS

\section{ABSTRACT}

This article was based on texts produced by high school students of the Farroupilha Federal Institute, Campus of São Vicente do Sul, in the Portuguese language. The central issue of the discussion is based on the analysis of the reproduction of racist discourses brought by students' texts. Because it is a social research, it is qualitative in nature according to Minayo (2001). The text discusses the ethnic issue in Brazil, the political perspective of the speeches and the sociocultural reality of the community that compose the IFFar. The theoretical contribution was constituted from authors such as Davis (2016), Freire (1996), Santos (2010), among others. As a conclusion, the need to discuss racism in school to foster empathy with non-dominant ethnic groups is presented.

Keywords: Speech. Education. Racism.

\footnotetext{
${ }^{1}$ Mestre em Práticas Socioculturais e Desenvolvimento Social (Unicruz). Bibliotecária no Instituto Federal Farroupilha, Campus São Vicente do Sul-RS. lais.costa@iffarroupilha.edu.br

${ }^{2}$ Doutora em Educação pela Universidade Federal do Rio Grande do Sul (UFRGS). Professora da Universidade de Cruz Alta (Unicruz).s.lauxen@unicruz.edu.br

${ }^{3}$ Mestrando em Educação pela Universidade Federal do Rio Grande-RS. Assistente Social da E.M.E.I. Casa da Criança Dr. Augusto Duprat, Rio Grande-RS. amaral.marcel@yahoo.com
} 
O desenvolvimento desta pesquisa-ação ocorreu no Instituto Federal Farroupilha - IFFar - Campus São Vicente do Sul, a partir de uma prática vivenciada em sala de aula, pensada conjuntamente pelo Núcleo de Estudos Afro-Brasileiros e Indígenas (Neabi), na disciplina de Língua Portuguesa, visando à abordagem do tema racismo com alunos do Ensino Médio.

A partir do tema alvo desta investigação, os alunos realizaram uma pesquisa bibliográfica sobre termos e expressões racistas da Língua Portuguesa; elaboraram um parágrafo crítico opinativo a respeito do tema racismo e produziram um texto dissertativo argumentando sobre esse tema. A partir das redações produzidas pelos alunos do primeiro ano do Ensino Médio foi possível analisar que há a presença de discursos que reafirmam o racismo. Observou-se que os discursos verbais presentes nos textos vão de encontro à teoria de democracia racial difundida pela hegemonia dominante. Justifica-se, portanto, a realização deste estudo sobre o tema racismo pelo fato de se tratar de uma instituição que atinge públicos que estão distantes dos grandes centros urbanos. Logo, encontra-se uma oportunidade de buscar compreender como é o posicionamento de parte do público interno da instituição sobre a questão étnico-racial.

\section{METODOLOGIA}

Tendo em vista a dimensão social que se pretendeu atingir com este estudo, utilizou-se a análise qualitativa que, segundo Minayo (2001, p. 14),

[...] trabalha com o universo de significados, motivos, aspirações, crenças, valores e atitudes, o que corresponde a um espaço mais profundo das relações, dos processos e dos fenômenos que não podem ser reduzidos à operacionalização de variáveis.

Os preceitos da pesquisa participante também foram norteadores para a construção metodológica deste trabalho, sobretudo por levar em consideração que "há na pesquisa participante um componente político que possibilita discutir a importância do processo de investigação tendo por perspectiva a intervenção na realidade social" (DEMO, 2000, p. 21).

Em se tratando de pesquisa participante, destaca-se que a atuação da pesquisadora Laís Braga Costa como membro no Núcleo de Estudos Afro-Brasileiros e Indígenas - Neabi - no Iffar, foi o principal fator que despertou o interesse na investigação, pois a aproximação com o tema de pesquisa deu-se por meio das discussões e dos estudos realizados no âmbito institucional sobre ações que visam a promover a inclusão social de negros e negras do Iffar.

Durante o mês de novembro de 2016, no Campus São Vicente do Sul foram realizadas atividades alusivas ao mês da consciência negra. Entre as atividades, faz-se importante salientar a exposição de fotos de pessoas negras da cidade de São Vicente do Sul; duas sessões de filmes do cineclube do Campus voltadas para a temática afro e rodas de conversa na biblioteca do Instituto Federal Farroupilha, quando os participantes falaram sobre identidade negra e racismo. Realizou-se, ainda, durante a roda de conversa com temática de racismo, a análise de algumas revistas de ampla circulação sobre a representatividade do negro, tais como as revistas Veja e Isto é. O que o grupo constatou foi 
uma ausência de modelos negros em fotos publicitárias e, nas poucas ocorrências de negros nas páginas das revistas, estas davam maior visibilidade a imagens associadas a matérias sobre futebol ou criminalidade.

Além disso, com o auxílio dos profissionais das áreas de Sociologia e de História, foi realizado um levantamento sobre os livros da biblioteca que abordam temas relacionados à negritude. Posteriormente, uma exposição foi montada em lugar de destaque na biblioteca, a fim de dar maior visibilidade às obras e, consequentemente, ao tema afro.

Nesse contexto de atividades pensadas conjuntamente com o Neabi, surgiu a ideia de realização, em sala de aula, de um trabalho que abordasse palavras e expressões da Língua Portuguesa que têm conotação racista. A atividade foi desenvolvida pela professora da disciplina para as turmas de primeiros anos do Ensino Médio, e consistia em realizar pesquisas sobre termos e expressões racistas da Língua Portuguesa, escoIher uma expressão e escrever um parágrafo opinando criticamente a respeito, e por fim, elaborar uma redação sobre o tema racismo. Para a discussão neste artigo foram selecionadas 4 amostras de redações sobre racismo, de um total de 31 textos.

\section{A QUESTÃO RACIAL NO BRASIL}

De acordo com Davis (2016), nos Estados Unidos há pelo menos dois aspectos no sistema de relações raciais que se diferenciam do Brasil: a segregação racial por lei, nos anos 60, e a regra de uma gota de sangue one drop rule, que estabelecia que os indivíduos que possuíssem uma gota de sangue negro eram considerados negros, independentemente da tonalidade da pele ou quaisquer outras características físicas.

As duas imposições, a segregação e a regra "uma gota de sangue", foram criadas com o objetivo de reafirmar a supremacia branca, mas acabaram favorecendo uma unidade dos negros, acima das barreiras de classe e de diferenças de tonalidade da pele. Especialmente a regra de uma gota de sangue, embora bastante repressiva, acabou por unificar a comunidade negra, visto que na sociedade norte-americana não há o mesmo sistema de classificação racial que existe no Brasil, em que o reconhecimento da negritude passa pela cor da pele, o que é denominado e difundido pelos movimentos sociais como colorismo, ou ainda pigmentocracia, que se baseia na classificação dos diferentes tons de cor de pele.

A questão do colorismo possui grande impacto sobre a autodeclaração racial no Brasil, pois se reconhecer negro, na sociedade brasileira, passa em grande parte pela tonalidade escura da pele. Esse fato faz com que muitos negros de pele clara se autodeclarem brancos e, assim sendo, observa-se que muitos indivíduos negros acabam, por consequência disso, negando uma identidade negra e deixando de explicitar a herança sociocultural de sua ancestralidade.

Na sociedade brasileira, a partir da miscigenação dos povos e da suposta democracia racial, há o entendimento de que a negritude do povo brasileiro foi diluída em prol da convivência harmoniosa de todas as etnias. Logo, deixa-se de explicitar grande parte da influência negra na sociedade brasileira. Sendo assim, a discussão sobre racis- 
mo é um tabu, pois parte-se da ideia de que todos os povos convivem em harmonia e que, portanto, o racismo no Brasil não existe, conforme exemplificam Soares; Braga e Costa (2002):

A escolha do Brasil como laboratório de civilização foi motivada principalmente pela crença difundida aqui e alhures de que nesta terra, em comparação com o contexto segregacionista norte-americano e o sul-africano, a democracia racial era um fato, fundamentado na miscigenação e na ausência de preconceito racial (p. 2).

A reflexão acerca da identidade negra e dos elementos sociais que corroboram para a explicitação do Brasil como um país racista é relevante para que se tenha presente que a construção de uma identidade sociocultural é parte de um processo coletivo e, assim sendo, as práticas cotidianas já impregnadas na sociedade brasileira contribuem para a manutenção do racismo. Atualmente, no Brasil e em outros países escravocratas, a situação dos homens negros envolve o encarceramento em massa. Em geral presume-se que esse seja um fenômeno masculino, porém ocorre que as mulheres desses presidiários tornam-se as únicas responsáveis pelos filhos e pela manutenção da família em todos os aspectos, portanto não seria correto afirmar que isso afeta apenas o homem negro, uma vez que atinge estruturalmente a população negra como um todo.

Outra questão sobre a normalização da ordem social a partir do racismo estrutural da sociedade brasileira observa-se a partir dos dados de Cerqueira e Coelho (2014), os quais apresentam estatísticas descritivas sobre as características pessoais das vítimas de estupro e demonstram que $51 \%$ dos indivíduos que sofreram estupro eram de cor preta ou parda. Esse dado expõe a situação de vulnerabilidade vivida por esse grupo da população brasileira e que, assim como nos Estados Unidos, segundo observa Davis (2016), também é de origem escravocrata e traz em sua organização social consequências decorrentes do período de colonização.

A cultura do estupro, que deslegitima a condição da mulher como ser humano, é ainda mais severa com a população negra, constituindo este grupo o que mais tem sofrido com a violência sexual, que se mostra sistemática desde o tempo da escravidão. Na clássica obra de Gilberto Freyre (1984) intitulada Casa-Grande \& Senzala, na qual é feito um resgate da formação histórica da sociedade brasileira, são várias as menções à objetificação da mulher escravizada pelos senhores da Casa-Grande. O estupro e os mitos em torno da depravação das negras da senzala revelam o sistema opressor da escravidão não somente no que diz respeito à questão da classe pela exploração de mão de obra, mas também do gênero e da raça, pois a inferioridade da mulher negra parte de princípios diferentes da subjugação da mulher branca. A violência sexual, a cultura do estupro e da violação do corpo negro ficam evidentes em Freyre (1984) quando o autor traz à tona a questão de saúde pública do final do século 19 (que envolvia a contaminação de sífilis, por meio do contágio sexual), quando comenta sobre a lenda de que os homens se curariam da sífilis se fizessem "sexo" com uma negrinha virgem.

Davis (2016) critica a visão da esquerda ortodoxa que afirma que classe é o centro da discussão das opressões. Segundo a autora, classe é um ponto importante a ser discutido, porém não se pode deixar de considerar a indissociação entre gênero e raça. Logo, não é possível pensar nessas categorias de forma isolada, por exemplo; o racismo impede a mobilidade social da população negra, o que acaba por gerar uma massa de negros pobres. 


\section{REPRESENTAÇÕES SOCIOCULTURAIS NO ENTORNO DO IFFAR CAMPUS SÃO VICENTE DO SUL}

Para que se possa ter maior clareza a respeito da diversidade sociocultural, no âmbito desta pesquisa, é necessário que se tenha presente de que forma se organiza o cenário que compreende a comunidade acadêmica do IFFar Campus São Vicente do Sul. Atendo-se às regiões Centro-Oeste e Vale do Jaguari, das quais é oriunda a maioria do público da instituição, observa-se que há uma diversidade cultural que é marcante nessas populações.

Nesse sentido, pode-se citar a influência da cultura alemã em cidades como São Vicente do Sul e Mata, da cultura italiana em Jaguari e Santiago e das etnias indígena e negra nas cidades de Cacequi, São Pedro do Sul e São Vicente do Sul. Além disso, o cenário que reflete o entorno do Campus São Vicente do Sul apresenta características que permitem afirmar que a comunidade interna e externa da instituição sofre uma forte influência das tradições gaúchas, por meio de representações culturais como rodeios, músicas e danças tradicionalistas, competições de laço em vaca parada e lida campeira.

Especificamente sobre a cidade de São Vicente do Sul observa-se que a localidade tem vocação agrária, destacando-se na pecuária com a produção de bovinos. Também há, na região, a presença de grandes latifúndios. Contrapondo-se a isso, a cidade possui um baixo índice de desenvolvimento econômico, segundo o Programa das Nações Unidas para o Desenvolvimento (PNUD, 2010), revelando uma desigualdade social significativa entre a população. A periferia do Campus São Vicente do Sul evidencia a vulnerabilidade social de parte da população vicentina. Os dados da situação social da população podem ser observados a partir da seguinte pesquisa:

Tabela 1 - Renda, pobreza e desigualdade no município de São Vicente do Sul

\begin{tabular}{lrrr} 
& 1991 & $\mathbf{2 0 0 0}$ & $\mathbf{2 0 1 0}$ \\
\hline Renda per capita (em RS) & 371,04 & 527,85 & 614,13 \\
\hline \% de extremamente pobres & 22,01 & 10,99 & 4,07 \\
\hline \% de pobres & 50,30 & 31,45 & 12,20 \\
\hline indice de Gini & 0,68 & 0,66 & 0,52
\end{tabular}

Fonte: PNUD, 2010.

Culturalmente, na cidade de São Vicente do Sul, a realização de festas é um ato bastante marcante, tanto que elas já se tornaram tradicionais na região Centro-Oeste do Rio Grande do Sul, como o carnaval de rua da cidade, que se destaca pela grande participação dos públicos das cidades vizinhas, e a Feira de Comércio da Batata- Doce Fecobat - que enfatiza o título da cidade de "Terra doce do centro-oeste gaúcho" e dá destaque para o comércio regional e, ainda, com a oferta de apresentações artísticas regionais e nacionais. Por fim, destaca-se a realização dos bailes de Kerbs, festa típica de origem germânica, tradicional no município de São Vicente do Sul, no mês de outubro, há mais de 50 anos. Durante a semana da festa são apresentados blocos com a vestimenta típica da cultura alemã, há a eleição da Corte do evento e a realização de bailes. 
Dado o contexto sociocultural da região em que se situa o IFFar Campus São Vicente do Sul, este reflete-se sobre a identidade dos atores sociais que formam a comunidade acadêmica. Estes atores sociais que formam a comunidade acadêmica do IFFar estão expostos a experiências multiculturalistas que põem em diálogo tradições culturais, como se percebe em São Vicente do Sul, onde há a manutenção de uma festa tipicamente alemã que se realiza em uma cidade que tem uma representação não branca significativa entre os munícipes.

Logo, a realização de um evento, há mais de 50 anos com grande popularidade entre os vicentinos, representa a historicidade dessa população, pois embora a representação de famílias de origem alemã ocorra mais no município de Mata, de onde se atribui a influência germânica na cidade, visto que até 1964 o município de Mata pertencia a São Vicente do Sul, pode-se afirmar que a tradição germânica está presente culturalmente na cidade e que é parte da identidade sociocultural da população.

O fato de os bailes de Kerbs possuírem tanta tradição em São Vicente do Sul, em um primeiro momento pode causar estranheza, visto que, pautando o que dispõe o senso comum, não se observa na cidade o estereótipo dos imigrantes alemães. Esse fato demonstra que a identidade de um grupo social passa por uma construção histórica, social e política, de modo que uma festa típica da cultura alemã pode arraigar-se em uma cidade que não possui significativa colonização desta etnia, indo ao encontro do que afirmam Gehlen e Radomsky (2015) sobre os atores sociais. Segundo eles, são os valores culturais que predominam na dimensão da identidade social ou sociocultural. Portanto somos complexos, unos e múltiplos ao mesmo tempo.

Considera-se importante a contextualização da influência cultural dos sujeitos que compõem a comunidade do IFFar Campus São Vicente do Sul, pois são elementos fundamentais para se pensar o discurso encontrado nos textos dos alunos de primeiro do Ensino Médio, com os quais se pretende pautar uma discussão sobre racismo, e que permitem compreender como é o posicionamento de parte do público interno sobre tal tema.

\section{A PERSPECTIVA POLÍTICA DA ANÁLISE DE TEXTOS}

Para a utilização de textos sobre o tema racismo como base para a discussão deste artigo recorre-se à linguista Antunes (2007), que em sua obra defende o texto como objeto de estudo para língua materna em sala de aula, e o discurso como uma ferramenta política. Baseando-se em seu livro Análise de textos, a autora aponta algumas possibilidades de como analisar textos sem reduzi-los a um simples instrumento para garimpar palavras que sejam substantivos, adjetivos, etc., pois, assim sendo, o entendimento do texto não ocorre. A autora enfatiza que a análise de texto tem caráter bem mais amplo e relevante do que a perspectiva morfologia-gramática.

Quanto à posição política do discurso, Antunes (2007) defende que todo exercício da linguagem se faz por meio de textos, pois qualquer pessoa quando fala ou escreve está produzindo um texto. Por este motivo não existe socialmente a atividade de formar frases soltas, portanto o elemento no qual a língua se realiza é o texto, ele é o elemento concreto da realização da linguagem, seja ele oral, escrito, multimodal ou qualquer outra modalidade. Neste sentido, as finalidades da análise de textos são muitas e ultrapas- 
sam a simples procura das categorias gramaticais e sobretudo vão além da simples identificação dos erros. A luta pela linguagem correta é também uma luta pela manutenção de um poder reduzido aos grupos que têm a possibilidade de se escolarizar.

Durante muito tempo se confundiu língua com gramática, mas a língua é mais do que apenas a gramática. Segundo Antunes (2007), são elementos a serem analisados em um texto o universo de referências utilizadas, o viés literário, jornalístico, político, de que lugar o autor do texto está falando, sobre o que é o texto, qual a finalidade, o que vai defender, refutar ou informar, qual a relação com outros textos.

....somente na cadeia do texto é que podemos decidir sobre o que é mais adequado, sobre o que deixa o trecho mais claro: se substituir a palavra por um pronome, por um sinônimo ou, simplesmente, repeti-la. Fora do texto quase tudo é adequado. Ou melhor quase tudo são apenas conjecturas. No texto é que as coisas se submetem a regularidades e restrições (ANTUNES, 2007, p. 90).

Além disso, a autora destaca a importância das relações entre frases e parágrafos e do uso de conjunções, preposições, locuções conjuntivas, locuções adverbiais, uma vez que são ferramentas que provocam diferentes efeitos no texto, pois ao usar "no entanto", “além disso", “aliás", "portanto", “mas", "embora”, "por outro lado", “ainda que”, "em segundo lugar", o que de fato importa não é o nome gramatical que essas expressões possuem, mas sim o sentido e o efeito que elas causam no texto. Corrobora com isso a afirmação da autora ao alertar que "a gramática, sozinha, é incapaz de preencher as necessidades interacionais de quem fala, escuta, lê ou escreve textos (ANTUNES, 2007, p. 51)". Outra questão importante mencionada por Antunes (2007) é a adequação vocabular, pois cada palavra tem um sentido particular, portanto é significativo no texto a escolha pelo uso de uma palavra mais branda, de eufemismos ou hipérboles, etc., porque cada palavra produz um efeito.

Sendo assim, a perspectiva política da análise de textos, adotada neste artigo, parte da premissa de que o discurso é uma prática social, e por esse motivo viabiliza que se analise de que forma as pessoas influenciam na construção da sociedade na qual se encontram, mediante práticas que contribuem para solucionar ou manter as opressões.

\section{ANÁLISE DO CORPUS}

Para Lélia Gonzales e Carlos Hasenbalg (1982), existem espaços e lugares que são naturais aos negros e aos não negros. Nesta concepção, o "critério ainda na contemporaneidade tem sido simetricamente o mesmo: a divisão racial do espaço" (p. 15). Na sequência serão analisados quatro textos nos quais, de modo geral, observa-se que o racismo é adjetivado como "reverso" e que há a concepção de vitimização do negro. Nota-se ainda a crítica notória ao Dia da Consciência Negra, bem como à valorização e/ ou exaltação de um dia voltado à "consciência humana", além da invisibilidade do crime de racismo no Brasil.

Texto 1: Luta por igualdade

Ainda hoje em dia o tema racismo vem sendo muito discutido. Eles, os negros, sofrem preconceito quase que diariamente, mas também eles praticam, não da de dizer que apenas sofrem. 
Na questão das cotas mesmo, pra quê cotas? Não querem igualdade? Que comece por aí. Dizem ser tão inteligentes, então pra quê precisam de cotas, eles mesmos fazem racismo com eles próprios na minha opinião.

Fora que se chamar uma pessoa de negra ou coisa assim posso até ser processada enquanto eu posso ser chamada de "branquela", sem que isso seja considerado racismo, ironia não?

Não sou a favor do racismo mas também não concordo com certas atitudes deles. Devem sim buscar igualdade, mas o que acontece em alguns casos não é bem isso.

Observa-se que o Texto 1 fala sobre um argumento bastante comum quando se discute sobre as desigualdades étnicos-raciais, que é o racismo reverso. Esse tipo de argumentação é bastante difundida em discussões na Internet e é pautada na ideia de que negros e brancos encontram-se em um patamar de igualdade quando se trata de discriminação por cor de pele. Logo, deixa-se de considerar os privilégios sociais proporcionados pelo tom de pele branca.

O argumento do racismo reverso é uma consequência da ideia de democracia racial difundida no Brasil, pois invisibiliza a restrição aos espaços de poder vivenciados pelas pessoas negras. Nota-se que no Texto 1 são relatadas situações cotidianas que envolvem comentários sobre tons de pele negra e branca, como se a opressão sobre os tons de pele tivesse o mesmo peso. As pessoas de pele branca não são oprimidas por causa da cor, e o fato de um branco ser chamado de "branquelo" não dificultará a ele a ascensão social, porque são os brancos que ocupam os lugares de privilégio, a representatividade nos espaços de poder é branca, o padrão de beleza é branco, a cultura com maior status social é a branca.

Discursos que demonstram a falta de reconhecimento do privilégio branco foram recorrentes nos textos dos alunos. Cabe destacar que no Brasil não existiu perseguição político-cultural voltada para a população branca, e sim para com as etnias negra e indígena, logo, observa-se que a concepção de racismo reverso trata-se de uma ferramenta que faz reafirmar a prática sociocultural do racismo.

Além da injustiça vivida por pessoas negras desde a escravização até os tempos atuais, com a discriminação racial nos diferentes espaços e com a aniquilação do corpo negro, soma-se a isso discursos injustos, que não consideram a historicidade da origem das opressões raciais. $O$ mesmo tipo de argumentação está presente também no texto a seguir:

\section{Texto 2: Todos humanos}

A história sempre relatou o índio como escravo, criado com a liderança de um branco. Assim os índios não tiveram como expandir-se ou mesmo elevar sua condição de vida.

Nem todo negro é ladrão, todos temos os mesmos direitos e deveres, as mesmas leis, mas se é assim por que a maioria deles estão na cadeia?

É a classe social que faz com que o negro, muitas vezes, tenha algumas vantagens, mas como eles vivem em lugares com pouca condição de vida essa vantagem não se torna a favor deles. 
Geralmente a família deles leva um histórico ruim, pais separados, mãe que não sabe educar corretamente, eles pensam que nunca conseguirão chegar em uma faculdade, fazendo com que eles não se esforcem para isso.

O Texto 2 apresenta, no segundo parágrafo, a afirmação de que nem todo negro é ladrão, partindo do princípio de que existe o senso comum de se associar a imagem do negro à criminalidade. Esse estereótipo presente na escrita do aluno deixa claro mais uma situação discriminatória para com a etnia negra.

No terceiro parágrafo o aluno refere-se a vantagens que os negros têm, o que mais uma vez, assim como no Texto 1 , remete à invisibilização da luta dos negros pela equiparação de direitos sociais negados a essa população em consequência da origem escravocrata do Brasil. No trecho final o aluno apresenta um estereótipo de família negra e atribui ao negro a característica de falta de esforço como justificativa para a pouca ascensão social, mais especificamente o não acesso ao Ensino Superior.

\section{Texto 3: Preto ou branco? Cinza!}

Um assunto complexo e expor a ideia não sei nem por onde começar, então começo refletindo meu título que demonstra uma cor neutra como deveríamos ser diante de pessoas negras, brancas, de etnias diferentes, nada muda nossa capacidade de ser alguém na vida.

Erramos ao nomear essa semana como a da consciência negra, devemos começar por mais que seja tarde e tudo mais, mas tentar mudar essa história, ela já enraizou sim, mas nunca é tarde para correr atrás assim como no amor, pecamos muito, mas uma boa conversa muda tudo, todos somos capazes de fazer o que bem entendermos. [...]

O terceiro texto apresenta já no título a premissa da democracia racial, e no decorrer da escrita recorre ao discurso da neutralidade. Segundo Freire (1996), toda neutralidade afirmada é uma opção escondida, logo, o discurso neutro é uma forma de colaborar com a opressão dos grupos que mais sofrem com o peso da desigualdade social.

Cabe salientar que a análise dos textos realizadas neste artigo baseia-se no aspecto sociocultural presente nos discursos dos alunos e que, portanto, as reflexões voltam-se a procurar compreender de que forma os discursos reproduzidos pelos atores sociais com os quais se realiza este trabalho reafirmam a prática do racismo. Observa-se que o discurso de neutralidade presente no terceiro texto reforça a ideia de que é desnecessária a discussão sobre a opressão de raça, visto que todas as pessoas são iguais.

Não há, porém, ainda no Brasil igualdade de oportunidade para negros e brancos, logo, uma postura neutra diante desse tema é uma forma de contribuir para a manutenção da injustiça social. A afirmação de Santos (2000) ao destacar que "as pessoas e grupos sociais têm o direito a ser iguais quando a diferença os inferioriza, e o direito a ser diferentes quando a igualdade os descaracteriza" (p. 47), ilustra a necessidade de que se pense na igualdade entre as pessoas, porém sem desconsiderar as peculiaridades que constituem a historicidade dos indivíduos.

\section{Texto 4: A branquisse}

Existem vários casos de racismo no mundo todo. Este problema é um dos maiores, depois da homofobia, pois ele vem de anos e anos, passado de geração em geração, numa forma de superioridade. Campanhas e campanhas são feitas anualmente, como uma forma para diminuir. 
Bilhões de pessoas no universo, várias etnias e cores e os negros por terem sido escravos devem sofrer preconceito até hoje? Na história apresenta-se fatos de brancos escravos, ou seja, isso não é motivo para tanto preconceito

O país tenta recompensar essas pessoas por tanto tempo de escravidão, porém estão tão preocupados com isso que deixam de exercer os direitos dos brancos e pardos, pela grande preocupação. Negros e brancos são iguais, sentem o mesmo que sentimos, fazem tudo que fazemos, não existe diferença, por isso acho que devemos ter direitos iguais.

Brancos, não somos superiores a ninguém, não temos o direito de humilhar ou rebaixar ninguém. Por ele ser de outra cor ele não é diferente, ele é igual. Não temos o direito de escolha de cor, mas temos o direito de escolha de pensamentos.

Esse texto menciona a homofobia como sendo um problema maior do que o racismo. Sobre isso cabe, mais uma vez, a reflexão acerca dos prejuízos do mito da convivência harmoniosa entre todas as etnias na sociedade brasileira, pois torna-se incomum vermos veiculadas na mídia hegemônica notícias sobre crime de racismo, a menos que alguma figura pública seja alvo de comentários racistas ou de injúria racial.

Crimes de maior gravidade, porém, como o extermínio da população negra periférica nos grandes centros urbanos, não são associados ao racismo, assim como a maior vulnerabilidade das mulheres negras para crimes de violência sexual também não é noticiada como consequência de opressão ligada à raça. Esse fato contribui para que se tenha a sensação de que o racismo não acarreta consequências graves para além da violência psicológica.

No terceiro parágrafo está presente a questão dos direitos conquistados arduamente pela população negra como sendo uma injustiça para com a população branca. $\mathrm{O}$ acesso dos negros aos espaços de poder repercute socialmente como uma ameaça à hegemonia branca.

Sobre a ascensão da população negra ter um sentido de ameaça aos direitos dos brancos, um exemplo trazido por Davis (2016), ocorrido no movimento sufragista nos Estados Unidos, relata que os argumentos que as mulheres brancas utilizaram para ter direito ao voto foi que, caso as brancas não votassem, os direitos dos brancos estariam ameaçados. Isso porque com a conquista do direito ao voto pelos homens negros, estes poderiam ter número suficiente para eleger representantes que defendessem os direitos dos negros; logo, isso seria uma ameaça à supremacia branca.

A discussão sobre o racismo dentro do movimento feminista norte-americano, que, segundo Davis (2016), pecou em considerar o grupo "mulheres" como sendo homogêneo e universal, é útil para refletir sobre a diferença da emancipação da mulher branca e a emancipação da mulher negra. Para a mulher branca, emancipação consistia em ter os mesmos direitos dos homens brancos, porém ainda a partir de uma organização social que reproduzia a opressão com outros grupos. Já a emancipação das mulheres negras possuía um peso mais radical, no sentido de se pensar um outro modelo de sociedade, sem que se reproduza a lógica de alguns privilegiados como opressores.

Entende-se que um dos pontos centrais para o debate sobre a questão racial seja de fato pensar sobre um novo modelo de sociedade, pois pensar a emancipação social dos grupos oprimidos segundo a mesma perspectiva do opressor gera um entendimento de que a única lógica possível para as relações sociais precisa estar baseada na do- 
minação e na exploração. Assim sendo, quando um grupo não hegemônico conquista direitos, por mínimos que sejam, os privilegiados pelo sistema capitalista entendem que passaram a ser explorados, pois a ideia de dominação está tão arraigada culturalmente que é impensável, para a maioria, um sistema de sociedade que não vise à dominação e à exploração e sim à igualdade de oportunidades.

\section{CONSIDERAÇÕES FINAIS}

Este artigo teve como intuito principal analisar os textos dos discentes das turmas de primeiros anos do Ensino Médio do IFFar Campus São Vicente do Sul a partir da temática do racismo e, nesse contexto, buscar compreender qual é o posicionamento de parte do público interno da instituição sobre as desigualdades étnico-raciais. Observou-se, a partir dos textos produzidos pelos alunos, que os discursos encontrados nas produções textuais reafirmam a ideia do discurso dominante. Muitas das abordagens feitas pelos alunos são a reprodução idêntica de discursos veiculados pela mídia hegemônica, por exemplo, a não necessidade de cotas raciais para ingresso no Ensino Superior, a vitimização dos negros e a vinculação da imagem dos negros à criminalidade.

Conforme afirma Freire (1996, p. 112), "se a educação não pode tudo, alguma coisa fundamental ela pode, se a educação não é a chave das transformações sociais, não é também simplesmente reprodutora da ideologia dominante", logo, entende-se que a reprodução do discurso dominante entre os alunos deve ser um motivo de inquietação para os educadores do Instituto Federal Farroupilha, pois alerta para a necessidade de desconstrução de conceitos preestabelecidos sobre racismo.

A escola é um ambiente propício para este fim, e assim sendo, o conhecimento acerca das acepções dos alunos sobre as relações étnico-raciais é uma ferramenta que pode auxiliar a instituição como um todo para o fortalecimento de ações que contribuam para uma prática educativa antirracista. Sobretudo porque, conforme já explicitado, as representações socioculturais do entorno do IFFar Campus São Vicente do Sul são constituídas a partir de influências eurocentradas, o que não contribui para o desenvolvimento de empatia e solidariedade para com outras etnias.

É importante que se discuta novas formas de pensar a sociedade que não estejam calcadas no paradigma estabelecido pelo capitalismo, segundo o qual para se ter privilégios sociais é necessário ser homem, branco, heterossexual, cisgênero, rico, magro. Aqueles que não se encaixam nessas exigências têm direitos fundamentais negados e são oprimidos por um padrão social que não contempla a pluralidade humana em todas as suas condições de existência.

A discussão feita neste artigo, a partir de textos de discentes, leva à reflexão sobre o potencial dos discursos para a reprodução de opressões, seja por meio de falas ofensivas ou do silenciamento dos grupos não dominantes. Por consequência do debate sobre a questão étnica pautado por brancos, difundiu-se a ideia de uma democracia racial no Brasil, onde todos os povos são iguais. O silenciamento do povo negro e o apagamento da identidade negra originaram um mal-estar social em torno da temática racismo, e por conta disso não se admite que o Brasil é um país racista e que a situação da população negra brasileira é desigual em vários aspectos sociais. 
Por não haver um reconhecimento do Brasil como um país racista, os debates sobre cotas raciais, legalização do aborto, descriminalização das drogas, redução da maioridade penal, ocorrem de forma simplista. As argumentações rasas acerca dos problemas citados não levam em consideração que a manutenção do status quo oprime e aniquila a população negra. As cotas raciais, por exemplo, não oprimem os brancos e sim oportunizaram que após mais de 120 anos da abolição da escravidão no Brasil, houvesse um olhar específico para essa população, à qual foi negado o acesso à escolarização, algo que não aconteceu com a população branca.

Enfim, o racismo é causa de morte, de exclusão e de injustiça e a reafirmação dessa prática é tão naturalizada na cultura brasileira que é comum ser difundida por meio dos discursos. As práticas diárias que invisibilizam a discriminação por raça estão envoltas em atitudes cotidianas bem-intencionadas, que defendem a neutralidade diante do debate racial, a igualdade de legislação para brancos e negros, pois todas as pessoas têm a mesma capacidade, porém são essas atitudes rotineiras que fortalecem o racismo estrutural, velado, existente na cultura brasileira.

\section{REFERÊNCIAS}

ANTUNES, I. Análise de textos: fundamentos e práticas. São Paulo: Parábola, 2007.

CERQUEIRA, Daniel; COELHO, Danilo de Santa Cruz. Estupro no Brasil: uma radiografia segundo os dados da Saúde (versão preliminar). Brasília: Ipea, 2014. (Nota técnica. Vol. 11). Disponível em: https://www. ipea.gov.br/portal/images/stories/PDFs/nota_tecnica/140327_notatecnicadiest11.pdf. Acesso em: 9 out. 2016.

DAVIS, Angela. Mulheres, raça e classe. São Paulo: Boitempo, 2016.

DEMO, Pedro. Metodologia do conhecimento científico. São Paulo: Atlas, 2000.

FREIRE, Paulo. Pedagogia da autonomia. 35. ed. Rio e Janeiro: Paz e Terra, 1996.

FREYRE, Gilberto. Casa-Grande \& Senzala. 23. ed. Rio de Janeiro: José Olympio, 1984.

GEHLEN, Ivaldo; RADOMSKY, Guilherme F. W. Atores sociais e identidades socioculturais. In: MEIRELLES, Mauro; MOCELIN, Daniel Gustavo; RAIZER, Leandro (org.). Atores sociais, diversidade e identidade. Porto Alegre: Cirkula, 2015. p. 19-36.

GONZALEZ, Lélia; HASENBALG, Carlos. Lugar de negro. Rio de Janeiro: Marco Zero, 1982.

MINAYO, M. C. S. (org.). Pesquisa social: teoria, método e criatividade. Petrópolis:

Vozes, 2001.

PNUD. Programa das Nações Unidas para o Desenvolvimento; IPEA. Instituto de Pesquisa Econômica Aplicada; FJP. Fundação João Pinheiro. Atlas do desenvolvimento humano: São Vicente do Sul, RS. 2010. Disponível em: http://atlasbrasil.org.br/2013/pt/perfil_m/sao-vicente-do-sul_rs. Acesso em: 5 nov. 2016.

SANTOS, Boaventura de Sousa. Por uma concepção multicultural de direitos humanos. In: FELDMAN-BIANCO, Bela (org.). Identidades: estudos de cultura e poder. São Paulo: Hucitec, 2000.

SOARES, Eliane Veras; BRAGA, Maria Lúcia de Santana; COSTA, Diogo Valença da. O dilema racial brasileiro: de Roger Bastide a Florestan Fernandes ou da explicação teórica à proposição política. Sociedade $e$ Cultura, Goiânia (GO): UFG, v. 5, n. 1, p. 35-52, jan./jun. 2002. 